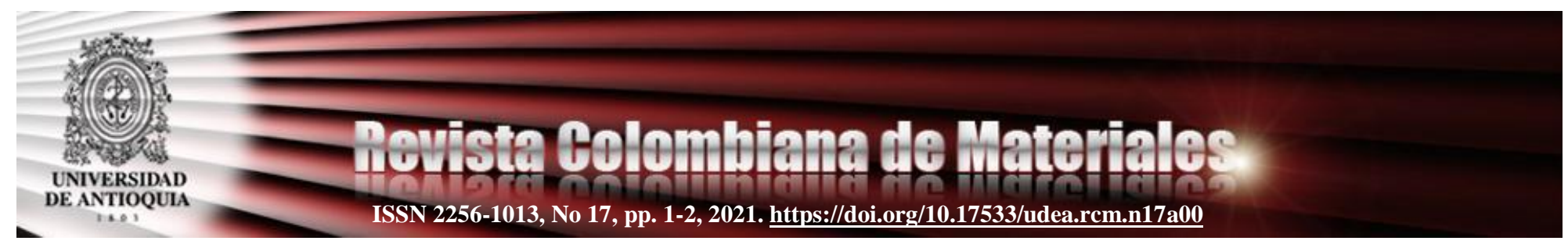

\title{
SOBRE EL ESTADO ACTUAL DE LAS ÓRTESIS, PRÓTESIS E IMPLANTES ÓSEOS EN COLOMBIA
}

\author{
D. Moreno \\ Investigador Postdoctoral, Grupo Biomateriales, Biomecánica e Ingeniería de Tejidos (BBT), Departamento \\ de Ciencia e Ingeniería de Materiales, Universitat Politécnica de Catalunya, 08019, Barcelona, España. \\ Investigador, Grupo de Investigación en Materiales y Recubrimientos Cerámicos GIMACYR, Universidad de \\ Antioquia UdeA, Medellín, Colombia \\ *daniel.morenod@udea.edu.co
}

En este número de la Revista Colombiana de Materiales se presentan algunos artículos de trabajos presentados en el " $1^{\text {er }}$ Simposio Nacional de Prótesis Ortopédicas en México: El Estatus Actual". Desde el número anterior se presentan algunos de los trabajos de este evento y ambas editoriales tenían el objetivo de mostrar el estado actual de las prótesis ortopédicas en México y Colombia, sin embargo, dicho estudio o seguimiento por algún organismo de salud colombiano no se ha realizado de manera minuciosa. Dicha falencia hace difícil el trabajo de analizar las tendencias y determinar los casos de éxito para ortopedistas y médicos especializados en la rehabilitación de pacientes con complejidades ortopédicas; igualmente, dificulta el papel de los investigadores para entender las tendencias de los dispositivos y materiales actualmente usados y aplicados en la ortopedia. El análisis para Colombia se limita entonces a boletines incompletos o a publicaciones científicas, que por lo general describen materiales que están en etapas de desarrollo temprana, aún no aplicables a los pacientes.

Aunque el Ministerio de Salud de Colombia reconoce dicha falencia, ha presentado algunos reportes en conjunto con el Departamento Administrativo Nacional de Estadística (DANE), de los que se pueden interpretar algunas tendencias respecto a las personas con discapacidades, específicamente que limiten o imposibiliten su independencia, por afectaciones ortopédicas. Se estima que casi un 2,0 \% de los colombianos padecen de discapacidad motriz, donde las principales causas están asociadas a accidentes de tránsito, víctimas del conflicto armado o patógenos [1]. Sin embargo, dichos datos no coinciden con los presentados por el Registro de Localización y Caracterización de Personas con Discapacidad (RLCPD), que en su base de datos tiene identificadas 611.700 personas con discapacidad motriz (alrededor del 1,2\% de la población colombiana). Se estima que entre el 10 y $20 \%$ de los discapacitados son amputados y necesitan una órtesis [2,3]. Igualmente, el número total de artroplastias (reemplazos articulares), como las de cadera $\mathrm{y}$ rodilla, que se hacen al año son desconocidas y solo se encuentran algunos datos de estudios, difíciles de extrapolar, que se hacen dentro de clínicas u hospitales de algunas ciudades del país [4,5]. Aún más complicado de analizar es el desconocido 
porcentaje de esta población afectada que ha sido tratada y poseen algún dispositivo o biomaterial que le ayude a tener una vida más "normal" en términos de autonomía motriz.

Para tener una idea de las investigaciones sobre biomateriales (metálicos, poliméricos, cerámicos o compuestos) compatibles con el hueso realizadas en Colombia, se pueden hacer análisis de bases de datos. Por ejemplo, haciendo búsquedas en Scopus con las palabras "bone implants" y afiliaciones de los autores en Colombia, se encuentran alrededor de 160 publicaciones hechas en los últimos 10 años. La misma búsqueda, pero con afiliación en España, arroja como resultado 1849 publicaciones. Esto se podría relacionar con la baja inversión del gobierno colombiano en la investigación en general y al poco apoyo del sector privado, dada la difícil transferencia de los conocimientos alcanzados por las universidades colombianas hacía la industria. El sector de la salud importa distintos materiales para atender las necesidades ortopédicas de los pacientes colombianos, donde se podrían presentar alternativas nacionales más económicas por la eliminación de los costos de importación y la producción local a menores precios.

Con este panorama, es claro que hay una considerable población del país que necesita intervenciones ortopédicas para mejorar su calidad de vida, pero que la deficiente vigilancia y seguimiento a las personas discapacitadas y a los procedimientos quirúrgicos ortopédicos han podido afectar la inversión pública o privada en la investigación y desarrollo de prótesis, órtesis y biomateriales óseos. Por ello, en esta Editorial se pretende llamar la atención e invitar al gobierno colombiano a un mejor seguimiento de las personas con afectaciones de la movilidad, la cantidad de artroplastias efectuadas por año y a apoyar la investigación de las universidades nacionales en temas ortopédicos para generar productos de gran beneficio a menores precios.

\section{REFERENCIAS}

[1] J.C. Cubillos Alzate, M. Matamoros Cárdenas, S. Perea Caro, Boletines Poblacionales: Personas con Discapacidad, Minist. Salud y Protección Soc. - Of. Promoción Soc. (2020) 16.

[2] S. Laverde, Colombia avanza en el desarrollo de prótesis mioeléctricas, (2015)2. https://www.elhospital.com/temas/Colombia -avanza-en-el-desarrollo-de-protesis-

mioelectricas+102438, (accessed April, 2021).

[3] C. Quintero Quiroz, A. Jaramillo Zapata, M.T. De Ossa Jiménez, et al., Estudio descriptivo de condiciones del muñón en personas usuarias de prótesis de miembros inferiores, Rev. Colomb. Médicina Física y Rehabil. $25 \quad$ (2015) 94-103. https://doi.org/10.28957/rcmfr.v25n2a1.

[4] C.M. González, C.M. Obando, C.A. Jaramillo, et al., Resultados clínicos de pacientes intervenidos con reemplazos articulares de cadera y rodilla en la Clínica Soma, año 2010, Rev. Colomb. Ortop. y Traumatol. $28 \quad$ (2014) 4-8. https://doi.org/10.1016/S01208845(15)30002-X.

[5] G.R. Escallón, J.M. Nossa, R.R. Ojeda, et al., Revisión de artroplastia total de cadera en el Hospital de San José y el Hospital Infantil Universitario de San José (2009-2012): frecuencia de la reintervención y la mortalidad, Rev. Colomb. Ortop. y Traumatol. $31 \quad$ (2017) 27-33. https://doi.org/10.1016/j.rccot.2017.01.001. 